\title{
Research on Content Design of Media Facade and Augmented Reality for Preschool Education
}

\section{Xinyi Shan}

Art College, Shandong Yingcai University, Ji'nan, Shandong, China

\begin{abstract}
With the advent of the 5G era, new media technology has been developed rapidly, in which media facade projection, augmented reality (AR) technology are also constantly infiltrating into the education industry and people's lives. On March 21, 2018, Songjiang District of Shanghai launched a wonderful open class of holographic teaching biology, which successfully brought new media technology into the classroom and made the classroom more vivid and easy to understand. Taking children as the object, this paper summarizes and compares the new media content classification and similarities and differences of applicable early childhood education from the perspective of media facade projection and AR content production. This paper aims to seek the application direction of new media in the process of preschool education, in order to promote the better development of early childhood education under the background of new media era.
\end{abstract}

Key words: new media technology; preschool education; media facade; augmented reality

\section{Introduction}

1.1 Objectives and background of the research

Since 2016, stories and news about VR (Virtual Reality) and AR (Augmented Reality) have been all over the streets. People have lamented that "the dark technology in movies is used to occupy the earth", and some media even praised 2016 as the first year of VR and AR. With the arrival of the $5 \mathrm{G}$ era, AR technology has been further promoted, and holographic projection technology, which was born half a century ago, has become hot again.

Preschool education has always been one of the most important stages in the education process. How to make children win at the starting line in terms of intelligence, emotion, and cognition has become an important training goal for parents and teachers. But different from the education methods of middle schools and even universities, children's lack of words and logic leads to the uniqueness of preschool education. It must rely on graphics, colors and novel forms to attract and guide children to accept knowledge. For the preschool education stage, visualized new media content is undoubtedly a good teaching method, and through high-tech virtual design and new media communication methods (like holographic projection, media facade projection, AR technology etc.), children can experience safety while ensuring safety. It can make children accept common sense and knowledge principles in life, mobilize children's interest in learning, and let them learn in "play" and learn in "experience".

Through collecting and sorting out various materials, this research analyzes the media facade projection and AR content design applicable to preschool education. And through the way of questionnaire survey, it understands the views of

Copyright (C) 2021 by author(s) and Frontier Scientific Research Publishing Inc.

This work is licensed under the Creative Commons Attribution International License (CC BY 4.0).

http://creativecommons.org/licenses/by/4.0/ 
parents and teachers on the new teaching reform combining facade projection and AR technology in the process of preschool education. Finally, the features of media facade projection and AR content design suitable for preschool education are summarized and analyzed to provide theoretical reference for the future production of new media content targeting children.

1.2 Range of the research

This research mainly takes children aged 3-6 as the research object and early childhood education as the entry point. In the $5 \mathrm{G}$ era of the continuous development of immersive experiential content of new media, by integrating the concept of facade projection technology and AR technology as well as content production methods, it seeks for media facade and AR content design that is more suitable for preschool education.

1.3 Methods of the research

The research method of this topic is based on the theoretical support of two kinds of new media technology, and several different types of content design that have been applied in early childhood education are screened and analyzed. At the same time, through the questionnaire survey of children's parents and teachers of different ages and different schools, the conclusion is drawn, so as to promote the better development of early childhood education under the background of new media era.

\section{Application of New Media Content Suitable for Preschool Education}

2.1 Application of facade projection in preschool education

Holographic projection technology uses interference and diffraction principles to obtain nearly real 3D (threedimensional) images. The development characteristics of preschool children's attention, memory, thinking and intelligence determine that preschool teaching should adopt intuitive teaching methods. Although there is still room for research and development of real holographic projection technology, media facade projection technology can temporarily replace holographic technology at present, to present similar visual effects. As a teaching aid, facade projection technology has the characteristics of stereoscopic, lifelike, interactive, immersive, story-telling and information richness. Its visual effect is far more than traditional teaching methods such as physical objects and multimedia.

\subsubsection{Facade projection technology visualizes knowledge}

In the teaching process, there will inevitably be a lot of boring text content, especially when children are the teaching objects. Due to the relatively young age of children, generally between 3 and 6 years old, their own self-control is weak, and unable to focus on something. In the traditional education model, teachers attract children's attention through physical interaction and exaggerated expressions. But with the progress of the times, children are gradually not satisfied with this way of teaching, more and more children began to be unable to focus on sitting in the classroom. Facade projection technology transforms rigid text into images and music, and transforms knowledge into animation, which is projected in front of children. In the process of teaching, teachers also flexibly apply this technology to teaching games. The novel teaching mode attracts children's attention, and the picture is close to their daily life, which effectively stimulates children's enthusiasm to participate in class.

\subsubsection{Facade projection technology creates a unique scene of preschool education}

Through 3D facade projection technology, an immersive classroom is created, and an interactive projection classroom is created by combining songs and scenes. This education method is deeply loved by children. And for educators, with such a scene, whether it is interactive games with children or do other educational work will be more handy. For example, Chinese company which called MCube Interactive has developed a simple sports game "Running on the Road" with interactive projection. In this projection game, children run on the projected virtual running road, and the projected road 
surface and surrounding environment will be transformed. At the same time, combined with the screen, you can compete with virtual cartoon images or other children. This kind of interactive game with children by using facade projection can not only allow children to get full physical exercise in the classroom without being affected by weather and environment, but also increase the interest, let children compete with their favorite cartoon characters, increase the enthusiasm for children's participation and improve their concentration.

\subsection{Application of augmented reality in preschool education}

Augmented reality refers to the technology of overlaying a layer of auxiliary information on a three-dimensional space or the physical world. Children in preschool education teaching are relatively young, lacking a comprehensive understanding of the basic knowledge of daily life and the independence and thinking ability in life. The application of augmented reality technology can inject new blood into the classroom, increase the interest of the classroom content, and attract the attention of children.

2.2.1 Augmented reality is changing the traditional way of teaching

In 2019, VX Entertainment has partnered with Jaguar Land Rover Public Ltd.C (JLR) jointly launched the first safe road in Beijing -- the Jaguar Land Rover Road Safety Little Guard Experience Area. JLR (China) and China Soong Ching Ling Foundation (SCLF)

jointly built this large-scale fixed venue for road safety education for children. The experience centered to integrate the boring traffic safety knowledge structure into 23 professional interactive experience facilities by means of AR, VR, somatosensory interaction, projection mapping, radar touch, laser trapping and other technology. It creates an intelligent travel experience full of childlike interest for children aged 3-8. Integrating this interactive experience into preschool education can enhance children's awareness of traffic safety. It provides scientific project operation guidance for children with the help of new media technology (AR, etc.), creates a multi-dimension and integrated one-stop experience environment, and thus creates a new teaching and education method.

\subsubsection{Augmented reality technology can better facilitate children's learning}

The burgeoning software company in Singapore which called Mixed Reality (MXR) launched the world's first AR civilian education product, wIzQubes, in 2006. It aims to help large class children and primary school students master basic knowledge, and fundamentally change the way children read through the use of AR technology. In 2012, Sony Corporation teamed up with Harry Potter author JK Rowling to create Wonderbook using AR technology and released its first production, Wonderbook: Book of Spells. In the Wonderbook, children can interact with the book, wave a wand and recite the incantations in Harry Potter, and let dragons "jump" out of the book and fly around the room. If you come across a fire in the book, you can use hand gestures to put out the flames, leaving smoke and dust behind when the flames go out. Whether it is wIzQubes from MXR or Wonderbook launched by Sony, the use of AR technology can well increase children's interest in learning, mobilize children's learning enthusiasm and improve their thirst for knowledge.

\section{Advantages and Disadvantages of New Media Technology in Preschool Education}

At present, VR, AR, XR, somatosensory interaction, facade projection and other new media technologies have not yet been fully popularized in preschool education, but we conducted a questionnaire survey with 250 parents and 50 teachers in two kindergartens in Jinan, Shandong. The survey covered parents of children aged 3-5 and preschool teachers aged 2540. Some of the results of the survey are shown in Figure 1. 


\section{Do you agree to increase the interactive content of new media \\ in the process of preschool education?}

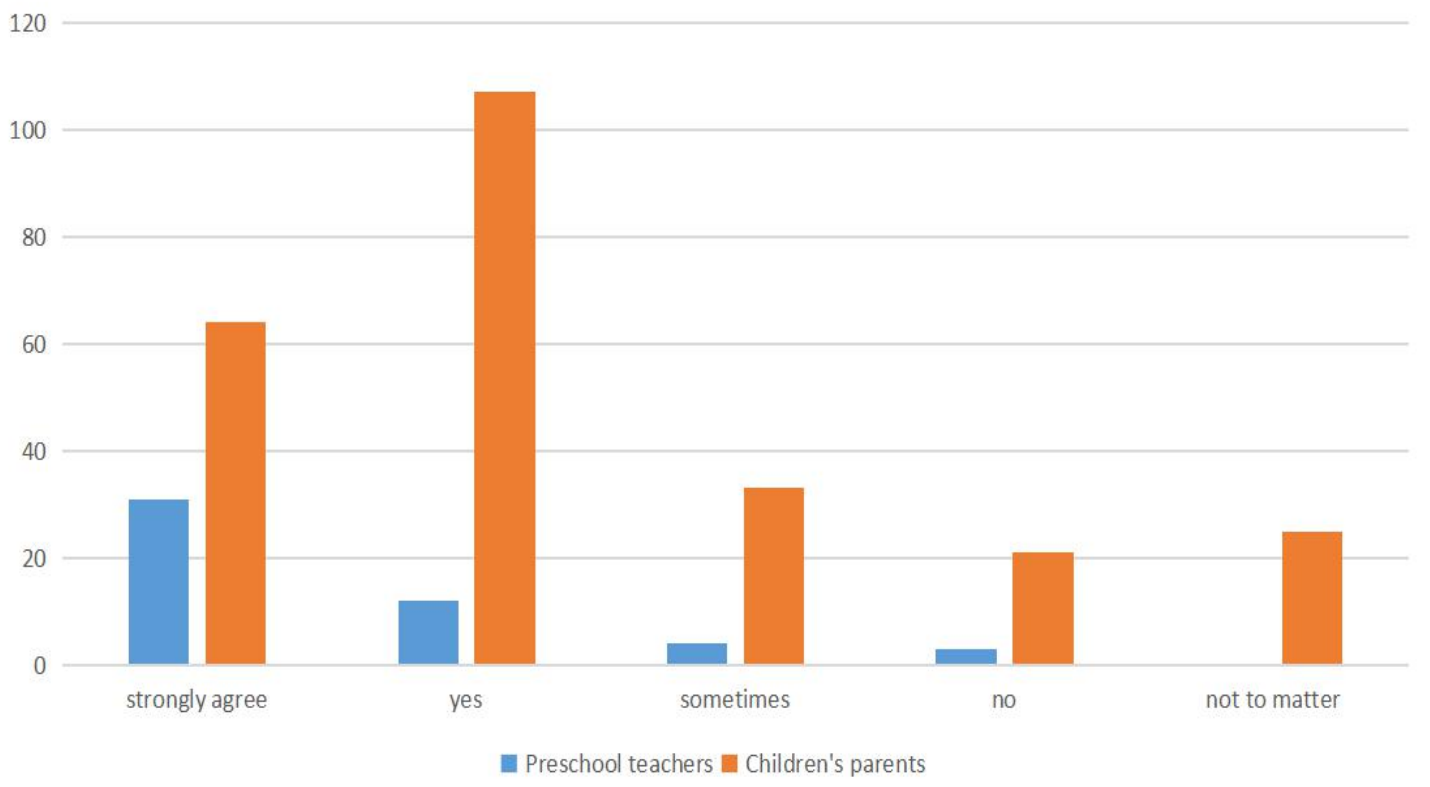

Figure 1. Survey results on parents' and teachers' recognition of children's acceptance of new media education

According to the survey results, more than $82 \%$ of teachers and parents support and hope to change the traditional preschool education model. Among them, preschool teachers support the integration of new media technology into classroom teaching more than their children's parents. Based on the analysis of the results of the 300 respondents, we summarized the advantages and disadvantages of new media technology in preschool education.

3.1 Advantages of new media technology used in preschool education

First of all, new media technology has changed the traditional teaching model to attract children's attention. In traditional preschool teaching activities, teachers take into account that children are fond of playing games and have strong hands-on ability, so they can integrate games to increase children's interest in learning when implementing teaching. However, most preschool teachers and parents believe that with the rapid development of science and economy, people gradually enter the network era, and our daily life and even education have been earthshaking changes. In order to make children better adapt to life and learn knowledge, teachers should change the traditional teaching philosophy and use new media technology to integrate into teaching activities. New media technology creates a good learning situation for children through sound and image, and creates a fresh and relaxed atmosphere for children, so as to attract children's attention and promote children to devote themselves to classroom teaching.

Secondly, the use of new media technology to combine sound and picture, this teaching method can also improve children's imagination and imitation ability. Every child is unique. Just because children are an independent individual, the level of development will be different. Therefore, in the preschool education stage, both teachers and parents should pay attention to nurturing and developing children's imagination. The use of new media technology (such as AR interaction, media facade projection, etc.) can be more intuitive to show a variety of fresh images to children, guide them to diverge thinking, improve children's observation ability, and also imperceptible improve children's ability to imitate.

Finally, by using new media technology, we can closely fit the originally boring knowledge into children's life and stimulate their enthusiasm to participate in class. Teachers flexibly apply new media technology to teaching games. The novel teaching mode attracts children's attention, and the picture is close to children's daily life, which effectively 
stimulates children's enthusiasm to participate in class. In addition, new media teaching not only opens children's horizons, but also vividly popularize daily knowledge.

\subsection{Disadvantages of new media technology used in preschool education}

New media technology can effectively expand children's vision, increase the scope of knowledge and help children to establish a complete thinking awareness in the teaching activities of children. However, our survey found that there are still some parents and preschool teachers think it is not necessary to change the traditional preschool education model. Among the 300 respondents we selected, $8 \%$ of preschool teachers and $8.4 \%$ of parents do not want to add new media technology to the existing preschool education. After conducting more in-depth interviews with these teachers and parents, we summarized two main disadvantages of using new media technology in preschool education.

For one thing is due to the relatively young age of children, generally between 3 and 6 years old, at this time, they are just beginning to develop in all aspects of their bodies, especially eyes, vision and so on. The daily teaching and entertainment of children combined with new media technology means that children will have more contact with electronic products, such as AR glasses (Google Project Glass) and interactive screens. The new teaching method is bound to attract more children immersed in it, and excessive use of eyes is one of the main concerns of parents and preschool teachers.

The second reason is that the current research on new media technology (especially VR, AR) mainly focuses on products. These developed APP and corresponding application programs make up for the shortcomings of traditional classroom teaching to some extent, but there are technical problems in these application systems, such as tedious design, fidelity of virtual space, high cost and the unknown caused by the use of these software. How to solve these problems is not addressed in the current study. In addition, the current application of these new media technology products in education is more focused on primary school and above age stage, and the scale is small, while the application of a variety of hightech new media technology in preschool education research is less. At the moment when new media education has not yet been fully popularized, if this new teaching mode is adopted, it will inevitably increase capital investment.

\section{Conclusions}

By analyzing the cases of products derived from new media technology and investigating the objects, we can find that among the new media technologies developed at present, facade projection technology and AR technology can change the traditional teaching mode and drive the enthusiasm of children's learning. By contrast, media facade is more suitable for integrating into preschool education at this stage, because it can be in the premise of not using glasses, screens and other electronic devices through the way of projection, so that children can contact the graphic picture. Reality technology, however, can be appropriate inserted into the process of preschool education, especially for children aged 5-6. Under the premise that teachers and parents strictly control the time of interactive learning, augmented reality technology enables children to actively participate in teaching from passive acceptance of knowledge to active exploration, active thinking and active operation.

In summary, this paper researches and analyzes the product examples of facade projection and AR content design suitable for preschool education. At the same time, it summarizes the advantages and disadvantages of new media technology used in preschool education through the investigation (the object of investigation is targeted at children's parents and preschool teachers) to find more suitable content design features for pre-school education. The application of new media technology in early childhood teaching not only conforms to the development trend of the society, but also meets the learning needs of every child, making the development of new media technology in early childhood teaching tend to be diversified, stimulate the strong interest and enthusiasm of children, so as to promote the efficiency of early childhood teaching. Through this study, we expect that with the development of science and technology and the 
popularization of new media technology, facade projection, AR and other new media technologies can shine in the field of preschool education. The traditional way of oral education will be replaced gradually, and the combination of vivid pictures and sounds will make the knowledge "live" and present a new learning environment for children.

\section{Conflicts of Interest}

The author declares no conflicts of interest regarding the publication of this paper.

\section{Acknowledgments}

This work was supported by the Key Project of Art Discipline in Shandong Province, 2019.06, (No. ZD201906135).

\section{References}

[1] Chen G.P. (2017). Research on Application of Virtual Reality Technology (VR) in Preschool Education. Journal of Chifeng University (Natural Science Edition), 33(11): 192-194.

[2] Fan K. (2015). Research on the Early Childhood Education Environment Supported by Augmented Reality Technology---Based on the Investigation and Experiment of a Kindergarten in Wuhan. E-education Research, 36(8): 61-65.

[3] He X.Q. (2019). A Survey of Augmented Reality Technology in the Field of Preschool Education. The Science Education Article Collects, (04): 148-150. 